\title{
High efficiency Bridgeless Unity Power factor CUK converter Topology
}

\author{
Aysha Kemaidesh AL-Kaabi ${ }^{1}$, Abbas A. Fardoun ${ }^{1}$ and Esam H. Ismail ${ }^{2}$ \\ ${ }^{1}$ Electrical Engineering Department \\ University of United Arab Emirates \\ P.O. Box 17555, Al-Ain, UAE \\ Phone: +971503385677, e-mail: afardoun@uaeu.ac.ae \\ ${ }^{2}$ Electrical Engineering Department \\ College of Technological Studies \\ P.O. Box 35007, Al-Shaab, Kuwait 36051 \\ Email: eismail@ieee.org
}

\begin{abstract}
A step-up bridgeless single phase ac-dc power factor correction (PFC) rectifier based on Cuk topology is proposed for high voltage battery charger application. The proposed topology consists of common input stage and parallel output stages. It utilizes one control signal over the whole line cycle. In addition, the proposed converter exhibits low inrush current and low magnetic emissions as classical Cuk topology. The bridgeless topology results in lower conduction losses as compared with conventional Cuk converter. Simulation and experimental results are presented along with the theoretical analysis.
\end{abstract}

\section{Key words}

Bridgeless rectifier, Cuk topology, DCM, low in-rush current and PFC.

\section{Introduction}

Power supplies with active power factor correction (PFC) techniques are required for wide range of applications for communication, automotive, computer and biomedical industries. All of these applications are required to meet industry standards such as the IEC 610003-2. In addition, it is highly recommended to meet new industry standards such as the 80 PLUS initiative. Many papers have been published in the literature to provide a solution for single-stage power factor correction (PFC) integrated topologies [1-7]. These solutions have been effective to provide cost-effective approach for achieving both the function of high PFC and fast output voltage regulation.

Most of the PFC rectifiers utilize boost converter at their front end. Boost converter provides many advantages such as natural power factor correction capability and simple control. However, low voltage applications such as telecommunication or computer industry an additional converter or an isolation transformer is required to step down the voltage. However, classical boost arrangement has lower efficiency due to significant losses in the diode bridge [1]. In addition, boost converters suffer from high inrush current which increases the cost of safety required disconnection devices between the load and the line voltage. To minimize the losses of the full bridge, many bridgeless PFC rectifiers have been introduced to improve the rectifier power density and/or reduced noise emissions [2]-[5] via soft switching techniques or coupled magnetic topologies.

Several non-boost bridgeless rectifiers have been published lately [6]-[10]. A bridgeless PFC rectifier based on Sepic topology is presented in [8]. However, the topology has only a step up capability like a boost transformer; however, an isolation transformer can be used to step down the voltage, hence increasing the cost and size of the rectifier. Even though Cuk converter topology is typically a lower efficiency converter, however it presents many advantages, such as isolation capability, step up/step down output voltage, continuous output current and lower electromagnetic emissions.

In this paper, high efficiency Cuk topology is proposed. The proposed topology is performance is evaluated based on component count, efficiency, total harmonic distortion (THD) and complexity. The proposed topology has an inherent low inrush current. In addition the proposed topology performance is compared with full bridge Cuk converter.

\section{The Proposed CUK PFC Converter: Operation \& Analysis}

Figure 1a shows the proposed Cuk topology. This converter consists of single input stage for both the positive and negative half cycles of the line voltage. On the other hand, it has two output stages connected to the switched input voltage; each stage operates during one half line cycle. The converter active components during the positive half cycle are shown in Fig. 1b while the converter equivalent circuit during the negative half cycle is shown in Fig. 1c. The proposed converter utilizes two switches $\left(\mathrm{Q}_{1} \& \mathrm{Q}_{2}\right)$. $\mathrm{Q}_{1}$ is turned on/off during the 
positive half-line cycle while $\mathrm{Q}_{2}$ is switched on/off during the negative half cycle. The converter has inherent high power factor when operating in discontinuous inductor conduction mode (DICM) because the line current is proportional to the input voltage. The converter operation during the positive half-line cycle is discussed below:

Stage $1\left[0, \mathrm{D}_{1} \mathrm{~T}_{\mathrm{s}}\right]$ : In this stage, switch $\mathrm{Q}_{1}$ is switched on and diode $\mathrm{D}_{\mathrm{o} 1}$ is reversed biased by the capacitor voltage $\left(\mathrm{V}_{\mathrm{c} 1}\right)$. The output diode $\mathrm{D}_{\mathrm{o} 2}$ is reversed biased by capacitor voltage $\left(\mathrm{V}_{\mathrm{c} 2}\right)$. The input voltage is connected to ground directly. The three inductors are charging up by the input voltage as shown in Fig. 2a. This stage ends when switch $Q_{1}$ is turned off.

Stage $2\left[\mathrm{D}_{1} \mathrm{~T}_{\mathrm{s}}, \mathrm{D}_{2} \mathrm{~T}_{\mathrm{s}}\right]$ : This stage starts after $\mathrm{Q}_{1}$ is switched off and diode $\mathrm{D}_{\mathrm{o} 1}$ turns on simultaneously as shown in Fig. 2b to provide current path for the output inductor current $\mathrm{L}_{\mathrm{o} 1}$. This stage ends when diode $\left(\mathrm{D}_{\mathrm{o} 1}\right)$ current goes to zero.

Stage $3\left[D_{2} T_{s}, T_{s}\right]$, this stage is reached when both the active switch and the output diode are off. The equivalent converter circuit of this stage is shown in Fig. 2c. Notice that there are no semiconductor devices conducting in this stage. The freewheeling stage ends when the new switching period starts. It shall be noted that to guarantee DCIM operation $\mathrm{D}_{2} \mathrm{~T}_{\mathrm{s}}$ must be less than $\mathrm{T}_{\mathrm{s}}$. Theoretical inductor currents waveforms over one switching cycle during the positive half cycle of the input voltage are shown in Fig. 3.
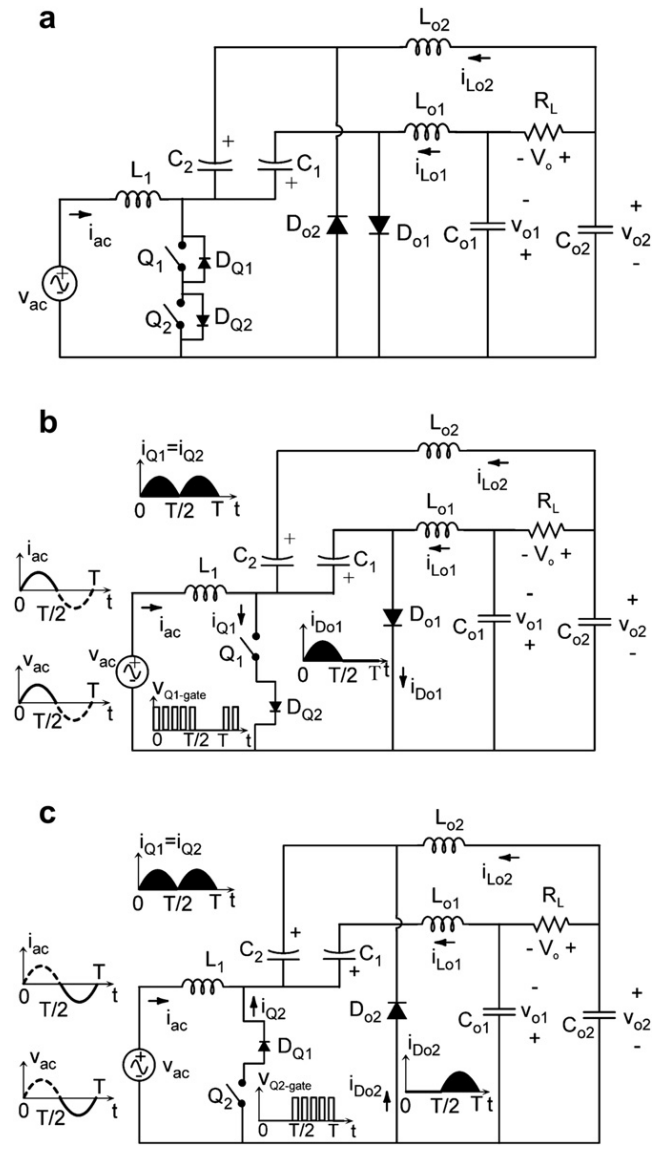

Fig. 1. (a) Proposed bridgeless Cuk rectifier (b) Positive half line cycle, (c) Negative half line cycle.
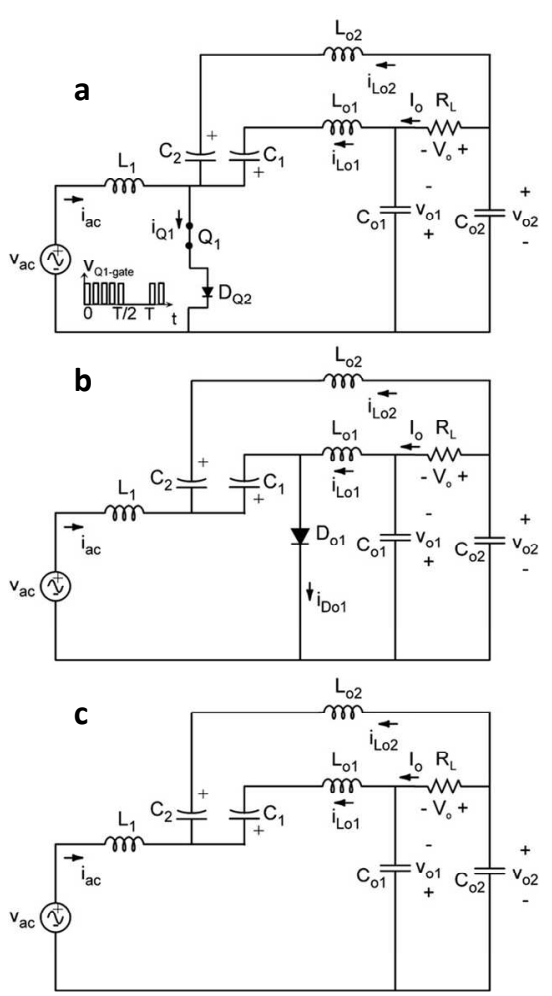

Fig. 2. The converter equivalent cycle over one switching cycle (a) First stage, (b) Second stage, and (c) Third stage.

\section{A. Steady State Analysis}

The proposed topology is analysed assuming lossless system and pure sinusoidal input voltage. In addition the output capacitors are assumed to be large enough to hold the output voltage constant over the whole line cycle while capacitors $\mathrm{C} 1$ and $\mathrm{C} 2$ are assumed large enough to hold the voltage constant over switching cycle. The input output voltage ratio is obtained by applying the volt second balance on the inductor and expressed as:

$$
D_{2}=\frac{2 D_{1}}{M} \sin (\omega t)
$$

where, $M=\frac{V_{o}}{V_{m}}$ is the conversion ratio of the average output voltage $\left(\mathrm{V}_{\mathrm{o}}\right)$ to the amplitude of the input voltage $\left(\mathrm{V}_{\mathrm{m}}\right)$ and $\omega$ is the line angular frequency

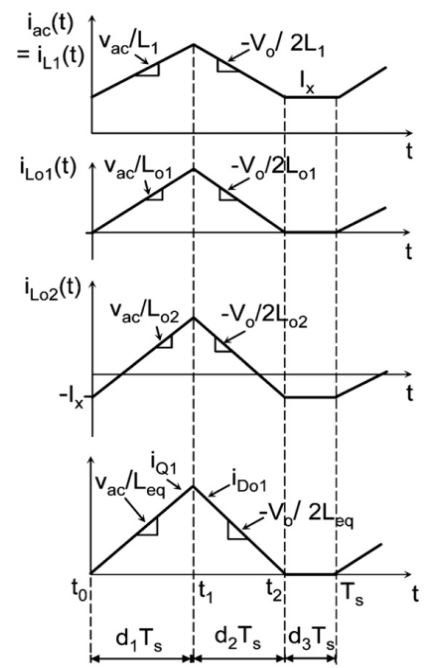

Fig. 3. Theoretical waveforms for the proposed converter. 


\section{B. Voltage Conversion Ratio $M(D 1, K)$}

The voltage conversion ratio as a function of the conduction parameter $\mathrm{K}$ is obtained by equating the input and output powers.

$$
M\left(D_{1}, K\right)=\frac{D_{1}}{\sqrt{2 K}}
$$

where, $\mathrm{K}$ is a unit-less parameter and can be expressed as:

$$
K=\frac{2 L_{e q}}{R T_{S}}
$$

\section{DICM Operation Constraints $\left(K_{\text {crit }}\right)$}

To operate in DICM, The following inequalities must be held:

$$
D_{1}+D_{2}<1
$$

The critical value of $\mathrm{K}$ as function of $\mathrm{M}$ to operate in $\operatorname{DICM}\left(\mathrm{K}_{\text {crit }}\right)$ is obtained by substituting Eq. (1) and (4) into Eq. (2).

$$
\mathrm{K}_{\mathrm{crit}}<\frac{1}{2(2 \sin \omega \mathrm{t}+\mathrm{M})^{2}}
$$

\section{Large Signal Model}

The input-output ratio can be derived as expressed in the following equation.

$$
M=\frac{V_{o}}{V_{m}}=\sqrt{\frac{R_{L}}{2 R_{e}}} \text { Where } R_{e}=\frac{2 L_{e}}{D_{1}^{2} T_{S}}
$$

Where $\mathrm{L}_{\mathrm{e}}$ is the parallel combination of inductors $\mathrm{L}_{1}, \mathrm{~L}_{\mathrm{o}}$ \& $\mathrm{L}_{\mathrm{o} 2}, \mathrm{D}_{1}$ is the duty cycle where switch $\mathrm{Q}_{1}$ is on and $\mathrm{T}_{\mathrm{S}}$ is the switching period of $\mathrm{Q}_{1}$. The network input and output port can be expressed as shown in Fig. 4.

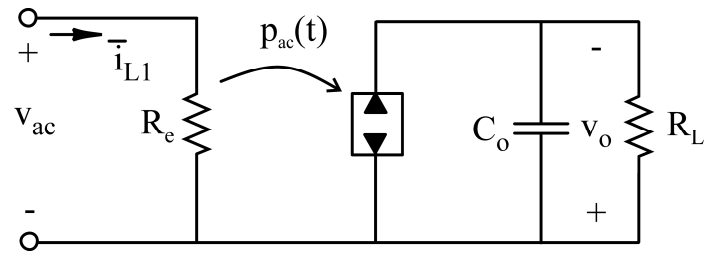

Fig. 4. Large signal model of the general averaged equivalent circuit in a converter operating DCM.

\section{E. Stresses}

The voltage stresses of the switches are shown in Fig. 5. The voltage and current stresses of the converter components are shown in Table I. All stresses are normalized with respect to the output voltage and load current. Converter stresses are required for design purposes.

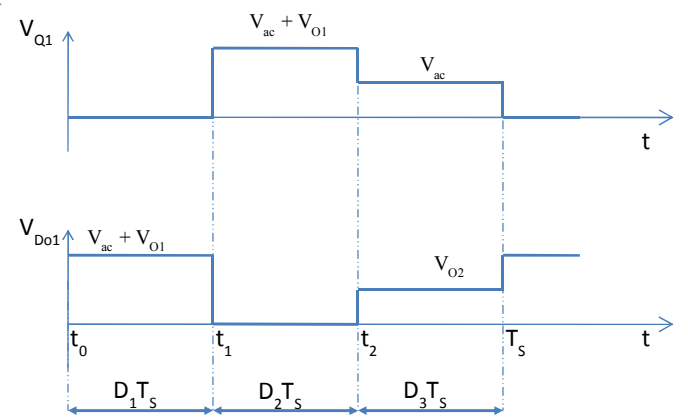

Fig. 5. The semiconductor switch and the diode voltage stresses.
Table I. - Current and voltage stresses

$\begin{array}{ccc}\text { Component } & \text { Voltage } & \text { Current } \\ \mathrm{Q}_{1}, \mathrm{Q}_{2} & \frac{2+M}{2 M} & M \\ \mathrm{D}_{\mathrm{o} 1}, \mathrm{D}_{\mathrm{o} 2} & \frac{2+M}{2 M} & M \\ \mathrm{C}_{1}, \mathrm{C}_{2} & \frac{2+M}{2 M} & \pm \frac{3}{2} \\ \mathrm{C}_{\mathrm{o} 1}, \mathrm{C}_{\mathrm{o} 2} & \frac{1}{2} & \frac{1}{2} \\ \mathrm{~L}_{1} & \frac{1}{2} & M \\ \mathrm{~L}_{\mathrm{o} 1}, \mathrm{~L}_{\mathrm{o} 2} & \frac{1}{2} & \pm \frac{3}{2}\end{array}$

\section{Simulation Results}

The proposed modified Cuk rectifier is designed for the following operating point: peak input voltage of 100 $\mathrm{V}_{\text {rms }}$, line frequency of $50 \mathrm{~Hz}$, output voltage of $250 \mathrm{~V}$, switching frequency of $50 \mathrm{kHz}$, and output power of 125 $\mathrm{W}$. For accurate simulation models, actual semiconductor devices are used in the simulation; D1N5402 are used for the diodes and irfb4332pbf for the active power switches. The circuit components used in the simulation are chosen as follows: $\mathrm{L}_{1}=2 \mathrm{mH}, \mathrm{L}_{\mathrm{o} 1}=\mathrm{L}_{\mathrm{o} 2}=50 \mu \mathrm{H}$. Moreover, an equivalent series resistor (ESR) of $20 \mathrm{~m} \Omega$ is placed in series with all the inductors to model the inductor losses and a $50 \mathrm{~m} \Omega$ ESR is placed in series with all capacitors to model the capacitor losses. Simulation studies were performed using ORCAD software package, to verify the analysis results.

The input voltage and current are in-phase as shown in Fig. 6(a). The total harmonic distortion in the line current is $0.17 \%$ and the efficiency is $94 \%$. The output voltage with respect to the input voltage is shown in Fig. 6(b), where the output voltage meets the requirements. It should be noted that the diode starts conducting after the switch is turned off and the current goes to zero before the end of the cycle which ensures DCM as shown in Fig. 7(a). Fig. 7(b) shows the three inductor currents over a switching cycle. The inductor currents have proportional slopes over the three different stages of a switching cycle. Thus, the three inductors can be coupled which lead to lower costs and smaller size. In addition, the three inductors are being charged by the input voltage when the $\mathrm{Q}_{1}$ is conducting, but when the diode $\mathrm{D}_{\mathrm{o} 1}$ is conducting, the three inductors are discharging through the output capacitors. The proposed rectifier harmonics is shown in Fig. 8 along with standard EN 61000-3-2 requirements. As shown in Fig 8, the converter satisfies EN 61000-3-2 requirements. 


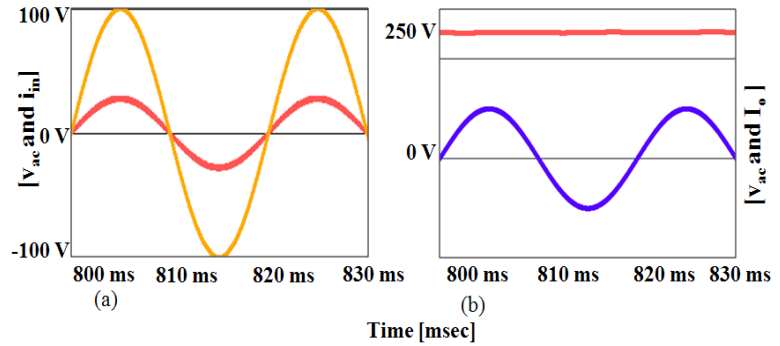

Fig. 6. Simulation results for the proposed rectifier: (a) Input current and input voltage, (b) Output voltage with respect to the input voltage.

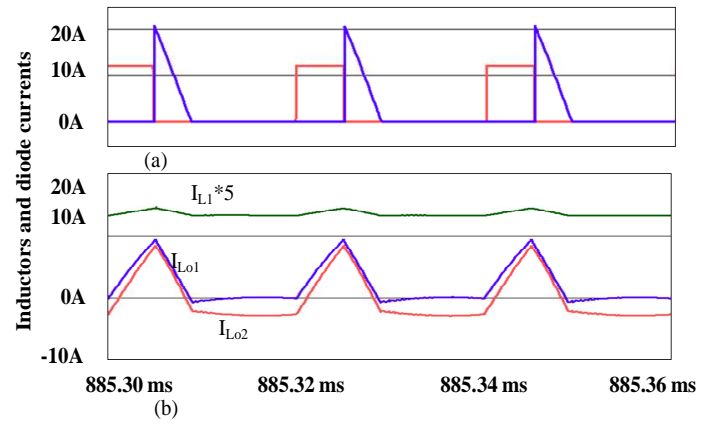

Fig. 7. Simulation results: (a) $\mathrm{V}_{\mathrm{Q} 1}$ and $\mathrm{i}_{\mathrm{Do} 1}$, (b) $\mathrm{I}_{\mathrm{L} 1}, \mathrm{I}_{\mathrm{Lo} 1}$, and $\mathrm{I}_{\mathrm{L} 02}$.

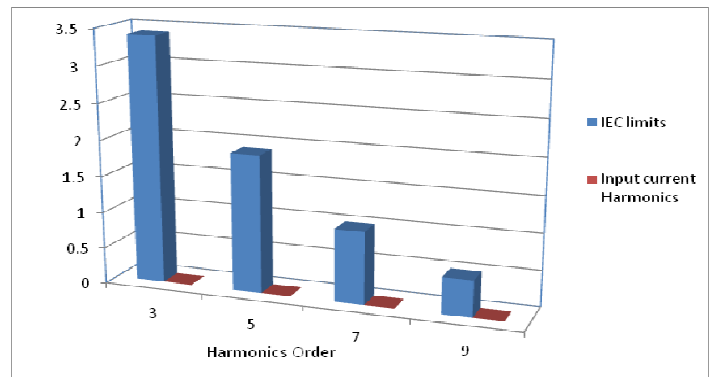

Fig. 8. Simulated input current harmonics of the proposed rectifier as compared with IEC 1000-3-2 standard

\section{Experimental Results}

The bridgeless DCM Cuk rectifier prototype test is validated at the same operating point as the simulation. A high frequency input filter is used at the voltage input to rectify the high frequency switching component of the line current. Fig. 9(a) shows the input current and line voltage. It can be seen that the line current and phase voltage are in phase. The load current and output voltage are shown in Fig. 9(b). The inductor currents $\mathrm{I}_{\mathrm{L} 1}$ and $\mathrm{I}_{\mathrm{Lo} 2}$ over a switching cycle are shown in Fig. 9(c), while Fig. 9(d) shows $\mathrm{I}_{\mathrm{Lo1}}$ and $\mathrm{I}_{\mathrm{Lo2} 2}$ waveforms. The current waveforms are in DICM as expected. The converter efficiency was measured to be about $94 \%$ at the desired operating point.

\section{Conventional Cuk versus the proposed Cuk Rectifier}

Comparison between the conventional Cuk and the proposed Cuk rectifier is shown in Table 2. The proposed bridgeless topology has fewer semiconductors in the current conduction path over the whole switching cycle. However, it has one additional switch compared with the conventional Cuk. Nonetheless, the switching losses are the same because only one switch is active over a switching cycle. The current stress in the output diode of the proposed rectifier is less because it conducts only over half line cycle. Also, the proposed rectifier has a floating switch which requires additional gating circuitry. In addition, the output voltage of the proposed topology is floating with respect to the input voltage. The efficiency for the conventional Cuk is $92 \%$ while it is $94 \%$ for the proposed Cuk rectifier. Moreover, the THD is $1 \%$, which is higher as compared to the THD of the proposed topology.
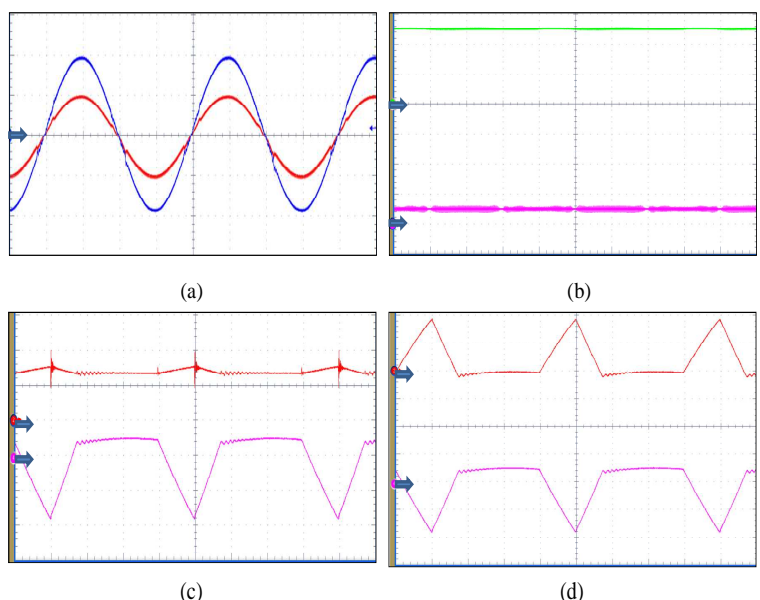

Fig. 9. Experimental results for the proposed rectifier: (a) Input current (3A/div.), input voltage (50V/div) over line cycle (time scale: $5 \mathrm{~ms} / \mathrm{div}$.), (b) Output voltage (100V/div), output current (1A/div) over line cycle (time scale: $5 \mathrm{~ms} / \mathrm{div})$, (c) $\mathrm{I}_{\mathrm{L} 1}(2 \mathrm{~A} / \mathrm{div})$ and $\mathrm{I}_{\mathrm{Lo2}}(5 \mathrm{~A} / \mathrm{div})$ over switching cycle (time scale: $\left.5 \mu \mathrm{s} / \mathrm{div}\right)$, (d) $\mathrm{I}_{\mathrm{Lo} 1}$ and $\mathrm{I}_{\mathrm{Lo} 2}(5 \mathrm{~A} / \mathrm{div})$ over switching cycle (time scale: $\left.5 \mu \mathrm{s} / \mathrm{div}\right)$.

Table II. - Comparison between conventional and bridgeless Cuk rectifier in DCM mode

\begin{tabular}{|c|c|c|}
\hline & $\begin{array}{l}\text { Conventional } \\
\text { Cuk }\end{array}$ & $\begin{array}{l}\text { Proposed Cuk } \\
\text { Rectifier }\end{array}$ \\
\hline Diodes & $\begin{array}{l}4 \text { slow and } 1 \\
\text { fast }\end{array}$ & 2 fast \\
\hline Switch & 1 & 2 \\
\hline $\begin{array}{l}\text { Current } \\
\text { conduction path } \\
\text { in stage } 1\end{array}$ & $\begin{array}{l}2 \text { slow diodes } \\
\text { and } 1 \text { switch }\end{array}$ & $\begin{array}{l}1 \text { body diode } \\
\text { and } 1 \text { switch }\end{array}$ \\
\hline $\begin{array}{l}\text { Current } \\
\text { conduction path } \\
\text { in stage } 2\end{array}$ & $\begin{array}{l}3 \text { diodes }(2 \\
\text { slow and } 1 \\
\text { fast) }\end{array}$ & 1 fast diode \\
\hline $\begin{array}{l}\text { Current } \\
\text { conduction path } \\
\text { in stage } 3\end{array}$ & 2 slow diodes & ----------------- \\
\hline \# of components & 10 & 11 \\
\hline $\begin{array}{l}\text { Integrated } \\
\text { magnetic }\end{array}$ & $\begin{array}{l}\text { One core for } 2 \\
\text { inductors }\end{array}$ & $\begin{array}{l}\text { One core for } 3 \\
\text { inductors }\end{array}$ \\
\hline $\begin{array}{l}\text { Deriver circuit } \\
\text { complexity }\end{array}$ & 1 non-floating & $\begin{array}{l}1 \text { floating and } 1 \\
\text { non-floating }\end{array}$ \\
\hline Ground & Non-floating & Floating \\
\hline
\end{tabular}




\section{Conclusion}

A bridgeless Cuk rectifier operating in DICM has been introduced. The Cuk rectifier has lower number of silicon components in the current path versus the conventional full bridge Cuk rectifier; hence higher efficiency is possible. The capability of this topology is verified via simulation and experimental results. Converter efficiency of $94 \%$ is achieved at low input voltage of $100 \mathrm{~V}_{\text {rms. }}$. Simulation and experimental results are shown and they corroborate theoretical analysis. The proposed circuit meets IEC-1000-3-2 requirements. The proposed rectifier at $125 \mathrm{~W}$ and full load has THD of $0.17 \%$.

\section{Acknowledgement}

This work was supported in part by the Emirates Foundation in the United Arab Emirates under Contract \# 2011/158.

\section{References}

[1] A. A. Fardoun \& E. H. Ismail, "Non-isolated Single Stage PFC Rectifier for Wide-Input Large Step-Down", International Journal on Power Electronics, vol. 2, no. 4, pp. 412-427, 2010.

[2] G. Moschopoulos and P. Kain, "A Novel Single-Phase SoftSwitched Rectifier With Unity power Factor and Minimal Component Count," IEEE Trans. on Ind. Electron., vol. 51, no. 3, pp. 566-575, June 2004.

[3] Y. Jang and M. Jovanovic, "A Bridgless PFC Boost Rectifier with Optimized magnetic Utilization," IEEE Trans. on Power Electron., vol. 24, no. 1, pp. 85-93, Jan. 2009.

[4] L. Huber, Y. Jang and M. Jovanovic, "Performance Evaluation of Bridgless PFC Boost Rectifiers," IEEE Trans. on Power Electron., vol. 23, no. 3, pp. 1381-1390, May 2008.

[5] A. A. Fardoun, E. H. Ismail, Ahmad J. Sabzali and Mustafa A. Al-Saffar, "New "Real" Bridgeless High Efficiency ACDC Converter", 27th annual IEEE Applied Power Electronics Conference (APEC), Orlando, pp. 317-323 Feb. 2012.

[6] M. Brkovic and S. Cuk, "Input current shaper using Cuk converter," in Proc. Int. Telecommun. Energy Conf., 1992, pp. 532-539.

[7] E. Mahdavi, M. and H. Farzanehfard, "Bridgeless SEPIC PFC Rectifier With Reduced Components and Conduction Losses" IEEE Trans. Ind. Electron., vol. 58, no. 9, p. 41534160, 2011.

[8] A. Sabzali, E. H. Ismail, M. Al-Saffar and A. A. Fardoun, "A New Bidgless PFC Sepic and Cuk Rectifiers With low Conduction and Switching Losses", $8^{\text {th }}$ International Conference on Power Electronics \& Drives Systems, PEDS 2009, pp550-556, November 2009.

[9] A. A. Fardoun, E. H. Ismail, A. J. Sabzali and M. A. AlSaffar, "A Comparison between Three Proposed Bridgeless Cuk Topologies and Conventional Topologies for Power Factor Correction," IEEE Transactions on Power Electronics,Vol. 27, no. 7, pp. 3292-3301, July 2012.

[10] M. R. Sahid, A. H. Yatim, and N. D. Muhammad "A bridgeless Cuk PFC converter", IEEE Applied Power Electronics Colloquium (IAPEC), pp. 81 - 85, 2011. 